\title{
Laban no século XXI: Revisões necessárias
}

MORAES, Juliana ${ }^{1}$

\section{Resumo}

A continuidade das idéias de Laban nos países vencedores da II Guerra dependeu de sua transformação em um sistema de análise de movimentos, que incluiu extenso mas discreto processo de renomeação, como, por exemplo: o conceito alma/espiritualidade foi adaptado para personalidade, e a dicotomia harmonia/desarmonia foi renomeada integração/ fragmentação.

Palavras-chave:

Rudolf Laban, coreologia, harmonia.

\section{Abstract:}

The continuity of Laban's ideas in the countries that won World War II depended on their transformation into a system of movement analysis, which included an extensive but discreet process of renaming concepts, such as: soul/spirituality has been adapted to the concept of personality, and the dichotomy harmony/disharmony was renamed integration/fragmentation.

Keywords: Rudolf Laban, choreology, harmony
1.

Doutora em artes cênicas pela UNICAMP, mestre em dança pelo Laban Centre (Londres), e bacharel em dança pela UNICAMP. Professora de performance no curso de Artes Visuais do Centro Universitário Belas Artes de São Paulo. Professora convidada no curso de bacharelado em teatro físico da Scuola Teatro Dimitri, na Suíça. juliana.moraes@belasartes.br 
1.

No artigo Laban's Secret Religion, a historiadora alemã Marion Kant defende que a ideia de harmonia de Laban teria origem em sua empreitada pessoal para construir a dança como meio de transcendência espiritual, uma "religião do ato" (KANT, 2002, p. 44), influenciada pela Maçonaria, a Rosa Cruz e a Ordem dos Templários, cujos preceitos aproximaram-no da ideologia Nazista. No livro Hitler's Dancers, escrito por Kant juntamente com Lilian Karina (publicado em alemão pela primeira vez em 1996 e traduzido para o inglês em 2003), as autoras empreendem uma ampla revisão histórica da dança alemã do período entreguerras, e afirmam que, com raras exceções (sendo a mais famosa o autoexílio a que se impôs Kurt Jooss na Inglaterra em 1933, após reiteradas ameaças aos integrantes judeus de sua companhia, e mais diretamente ao seu compositor Fritz Alexander Cohen), a grande maioria dos artistas ligados à dança expressionista alemã (Ausdruckstanz) se beneficiou da atenção que esta arte recebeu da burocracia nazista em forma de incentivos financeiros e, especialmente, pela organização de classe que o regime promoveu. Estranhamente, enquanto todas as outras linguagens artísticas engajadas nos movimentos das vanguardas do entreguerras minguou, a dança expressionista floresceu e conseguiu inclusive diminuir sobremaneira a influência do balé clássico em território alemão, afirmando-se como uma arte genuinamente nórdica e ariana.

O livro tem três partes. Na primeira, Lilian Karina, ex-bailarina clássica do entreguerras na Alemanha, que se exilou na Suécia para escapar do nazismo, faz uma incursão nos arquivos da época para desvendar o que acontecera com muitos de seus companheiros. Em sua busca, descobrimos que os documentos que ligam importantes nomes da dança alemã ao regime nazista tinham sido guardados pela burocracia da Alemanha Oriental e não tinham sido visitados em 40 anos. Em 1986, depois de um cansativo período em busca de autorizações, Lilian conta que no prédio da administração militar soviética, "o material veio coberto de pó e amarrado por uma corda. Os grossos arquivos e pacotes empoeirados e desordenados claramente não haviam sido vistos por ninguém e provavelmente estavam lá desde o período nazista" (KANT; KARINA, 2004, p.4).

Na segunda parte do livro, Marion Kant reúne as informações contidas nos muitos documentos descobertos e remonta a aproximação entre o nazismo e importantes figuras e associações da dança alemã, incluindo praticantes do balé clássico, de danças sociais e ilustres inovadores da Ausdruckstanz. 
Segundo Kant, a burocracia do regime, que pretendia se instaurar em toda teia social como forma de controle estatal sobre o indivíduo, fez com que os artistas da dança moderna vislumbrassem a possibilidade de ascender e ganhar espaço na luta feroz que havia anos travavam contra o balé clássico nos teatros do Estado. Ela conta como figuras ilustres, especialmente Rudolf Laban e Mary Wigman, lutaram dentro do regime na tentativa de estabelecer as bases para a nova dança genuinamente alemã.

Nas últimas linhas de seu texto, Lilian Karina resume o que ocorreu historicamente com as teorias labanianas. Segundo ela, depois de sua queda dentro da burocracia nazista, devido a desentendimentos internos com o poder centralizador de Goebbles, Laban se exilou na Inglaterra, onde alguns de seus importantes discípulos - também em exílio - o acolheram. Foram eles que, segundo ela, trabalharam para transformar as ideias do mestre num sistema de análise de movimentos e num instrumento pedagógico, limpando-o da visão ideologizante e ocultista de Laban. Neste sentido, ela credita a Sigurd Leeder, Albrecht Knust e Lisa Ullman a perpetuação do sistema em algo amplamente utilizado hoje em dia, em todo o mundo (KANT; KARINA, 2004, p. 60).

O grupo de estudantes que se formou na escola Art of Movement Studio (Estúdio da Arte do Movimento), fundada por Rudolf Laban e Lisa Ullman em Manchester, em 1948, foi a primeira geração inglesa de discípulos que renovaria, uma vez mais, os conceitos do mestre e seguiria no sentido de criar uma sistematização, mesmo que isso fosse contra os ideais de Laban. Entre eles estavam Warren Lamb, que lançaria as bases para uma aproximação efetiva entre Eukinetics e Choreutics; Marion North, que se aprofundou na relação entre movimento e aspectos psicológicos da personalidade e dirigiu o Centro Laban de Londres por mais de 20 anos, e Valerie PrestonDunlop, grande conhecedora de Choreutics, Labanotação e disseminadora da Motif Writing (Escrita de Motivos), que ofereceria conceitos novos para o movimento no espaço e é há décadas referência no que passou a denominar de Estudos Coreológicos.

Aos poucos as ideias de Laban foram transformadas para se adequarem ao contexto inglês e americano (nos EUA, Irmgard Bartenieff as expandiu para o campo da fisioterapia e terapia somática), sendo incorporadas no ensino, na psicologia, em terapias corporais e no ambiente de trabalho - muito mais do que diretamente em coreografia. Entretanto, para que este processo desse certo, era preciso ignorar suas atitudes em relação ao Nacional Socialismo ou oferecer explicações 
morais aceitáveis. Sendo assim, Laban entrou para a História como um artista que ficou na Alemanha para defender sua dança até que sua vida se tornou insustentável e o exílio em 1937 a única opção. Ao rememorar os anos passados no Art of Movement Studio, Warren Lamb diz que "nós todos tínhamos a impressão de que ele era um refugiado do regime nazista" (apud McCAW, 2006, p. 29), e segue dizendo: "Eu realmente acredito que ele foi ingênuo o suficiente para pensar que poderia influenciar a liderança nazista para a sua maneira de ver a vida, o movimento e a criatividade individual" (Ibidem, p. 29). Kant esclarece que após a Segunda Guerra mundial "dançarinos alemães eliminaram a terminologia abertamente nazista, rescreveram suas biografias para omitir o período de 1933-45 ou se colocarem como vítimas do regime" (KANT; KARINA, 2004, p. x).

2.

Talvez uma das ideias de Laban deva receber atenção especial devido à transformação radical que ela operou na história da dança ocidental e nas pesquisas sobre o movimento: sua certeza absoluta na relação íntima entre movimento e interioridade. "Dança como meio de transcendência era uma escolha muito incomum, daí também jaz a originalidade de Laban" (KANT, 2002, p. 48). Segundo North, "Laban disse que o movimento 'é a expressão externa de energia viva interna"' (NORTH, 1972, p. 39), localizada num lugar que ele denominava de terra do silêncio - "uma paisagem escondida e esquecida está lá, a terra do silêncio, o reino da alma" (LABAN, 1975, p. 89).

Laban procurou reconfigurar o corpo como unidade e se contrapôs ao dualismo cartesiano e sua prerrogativa mecanicista que o balé clássico havia séculos representava. Até o início do século XX, o balé havia se consolidado como estética dominante na dança erudita ocidental; suas peças, hoje de repertório, operam na separação dramatúrgica entre a pantomima, que leva o libreto adiante, e os momentos de dança pura com sequências codificadas de passos (KATZ, 2011). Para Laban, esse tipo de codificação seria restritiva do espírito humano e a criação deveria se dar a partir das várias possibilidades do movimento, que ele tentou compreender em termos de princípios gerais. "A genialidade de Rudolf Laban foi que ele codificou os componentes do movimento de maneira a fazer com que um estudo disciplinado fosse possível" (LAMB apud McCAW, 2006, p. 16).

Se Laban não entrou para a história como um grande coreógrafo, alguns de seus mais importantes discípulos fizeram de suas proposições as bases para grandes inovações artísticas. 
Entre os mais famosos destacam-se Kurt Jooss e Mary Wigman que, apesar de desenvolverem poéticas diversas e terem visões bastante distintas em relação à dança e ao movimento, criaram as bases para uma revolução na dança moderna, levada adiante e reconfigurada no pós-guerra em muitos cantos do mundo (é reconhecida a influência da Ausdruckstanz nos trabalhos das primeiras gerações da dança moderna americana, principalmente através das inúmeras turnês de Mary Wigman pelos EUA e depois o estabelecimento de uma filial da sua escola em Nova York, em 1931, dirigida por Hanya Holm). A crença no valor do movimento como expressão inequívoca do espírito humano levou Wigman ao extremo de nomear seu trabalho de Dança Absoluta. Já Jooss, mais comedido, criou para si o termo Tanztheater (Dança-teatro), posteriormente renovado e internacionalmente reverenciado pelo trabalho de sua aluna Pina Bausch.

É comum na história da dança teóricos identificarem como uma das mudanças fundamentais da dança moderna em relação ao balé clássico o reconhecimento de que o elemento essencial dessa linguagem artística seria o movimento (LEPECKI In HEATFIELD, 2004, p. 120-127). A partir daí, a dança teria se libertado da música e da ideia do "passo" (que seria um movimento mais nobre do que os demais e consequentemente digno de estar no palco). Entretanto, tal afirmação parece mais adequada às investidas da dança abstrata dos anos 60 e 70 do que à primeira geração da dança moderna, seja europeia (marcadamente alemã) ou americana. Pois para os primeiros dançarinos modernos, o que importava era reconhecer no movimento a possibilidade de se acessar lugares recônditos da natureza humana. Ou seja, a dança havia se libertado da ideia do passo codificado para entrar no universo do movimento como expressão da interioridade (relativa a uma suposta "verdade" maior).

Interioridade, para Laban, relacionava-se, inicialmente, à espiritualidade e mais especificamente à alma humana; entretanto, quando de sua mudança para a Inglaterra ele começou a modificar suas acepções para a ideia de personalidade. Tal transformação teórica fica clara em seu livro Effort, escrito em 1947 conjuntamente com o engenheiro inglês F. C. Lawrence, e nos discursos de sua discípula Marion North. Este talvez seja um dos maiores exemplos da adaptação prática de seu modelo teórico depois da guerra. Entretanto, tal adaptação é parcial se levarmos em conta que a ideia de personalidade veiculada por Laban e disseminada por discípulos importantes como Marion North, mantém as características de uma paisagem escondida — semelhante à sua definição inicial da "terra do silêncio". 
Se nós aceitamos que a maneira como uma pessoa senta, caminha e faz gestos tem qualquer relevância em como ela está pensando ou sentindo, então é somente um passo pequeno para a ideia de que uma análise mais sutil e profunda da composição do movimento possa levar a uma maior compreensão da personalidade.

(NORTH, 1972, p. 12)

Outra adequação teórica importante que se desenvolveu entre os discípulos de Laban - especialmente Irmgard Bartenieff, Marion North e Trudi Scoop, mas que pode ser notada em discursos de terapeutas ligados indiretamente a essa genealogia como Mary Whitehouse (que estudou com Wigman) - é a incorporação da dicotomia conceitual harmonia/desarmonia renomeada integração/fragmentação. Assim, a ideia de Laban de que indivíduos psicologicamente harmônicos se moveriam harmoniosamente, enquanto indivíduos psicologicamente desarmônicos se moveriam também desarmoniosamente, foi se transformando na ideia, influenciada pela terminologia jungiana, de subjetividade integrada versus subjetividade fragmentada, associando a normalidade aos parâmetros de integração (harmonia) e a anormalidade aos parâmetros de fragmentação (desarmonia), que poderiam ser identificados e tratados pelo movimento. "Para Laban harmonia equivalia à condição para transcendência, para se superar a matéria física, corporal" (KANT, 2002, p. 49). North afirma que "os doentes mentais sempre revelam em suas características de movimentos e hábitos variações muito definitivas e distorções da escala da 'normalidade'" (1972, p. 14). Segundo Whitehouse "movimento é nosso comportamento, há uma conexão direta entre como somos e como nos movemos. Distorção, tensão e inatividade em nossos movimentos é distorção, tensão e inatividade em nós" (apud BANNERMAN-HAIG, 2002). Para Trudi Scoop, "é a interação harmônica entre psique e soma que promove um funcionamento livre de conflitos" (LEVY, 1992, p. 76).

Apesar da transformação de suas ideias num sistema, salvando-as para a posteridade no seio dos países vencedores da guerra, há limites para o grau de limpeza possível. A harmonia, conceito que permeia todas as suas teorias e sem o qual muitas de suas ideias não se sustentam, talvez seja o limite final para tal empreitada. Não há como contornar esse entrave teórico tentando encontrar respostas práticas e ideologicamente limpas. Infelizmente, o desejo de construção do corpo harmônico, que guiou Laban em suas incursões, é justamente aquilo que o compromete ideologicamente, pois só pode ser compreendido de fato se retornarmos suas ideias às suas origens - como preceitos para a criação de uma "religião do ato", da qual ele seria o grande líder. Kurt Jooss conta 
que, ao estudar com Laban em 1920, teria ouvido a seguinte frase do mestre: "Você verá a dança se desenvolver enormemente neste século e ela será a salvação da humanidade" (apud MARKAND, 1993, p. 45)

Como dito anteriormente, a continuidade das ideias de Laban nos países vencedores da guerra, especialmente Inglaterra e EUA, dependeu da sua transformação num sistema prático de análise de movimentos, que incluiu um extenso porém discreto processo de renomeação de conceitos. Entretanto, após análise mais detida notamos que por baixo dessa nova roupagem algumas das ideias de Laban (e infelizmente muitos de seus preconceitos) foram mantidas, num processo extremamente inteligente iniciado propositadamente por seus primeiros discípulos diretos e perpetuado, inconscientemente, pelas gerações subsequentes.

3.

Ao nomear os quatro fatores do movimento, Laban relacionou-os com estados psicofísicos específicos: espaço/atenção, tempo/ decisão, peso/sensação e fluência/emoção. É importante notar que ele não associa o estado subjetivo somente às emoções, mas sim a quatro dimensões distintas e que a análise desses fatores combinados indicaria o estado subjetivo no momento da ação. Por exemplo, um motorista experiente pode errar o caminho costumeiro ao ser tomado de forte emoção, ou seja, ele deixa de prestar atenção (fator espaço) no momento em que a emoção (fator fluência) o toma. Num outro exemplo, todos os movimentos corriqueiros do dia a dia devem ser feitos com funcionalidade, entretanto, quando uma pessoa é tomada por forte emoção os movimentos mais simples (como quebrar um ovo ou lavar a louça, por exemplo), tornam-se difíceis, pois a fluência (ligada à emoção) interfere no ritmo das ações, entrando no lugar de um fator ou outro (posteriormente, Warren Lamb relacionaria a fluência à precisão com o intuito de diminuir os aspectos "místicos" dos conceitos de Laban, evitando as generalizações e confusões que ligar fluência às emoções suscitavam).

As teorias de Laban sobre as relações de afinidade entre dinâmicas de movimento e estados psicológicos podem ser didaticamente estudadas nas peças de seus discípulos. A bruxa coreografada por Mary Wigman (Witch Dance, 1914) é grotescamente forte e, portanto, seus movimentos são fragmentados, diretos, acelerados e impactantes. Já a figura da morte de Kurt Jooss, em A Mesa Verde (1932), contém uma nobreza em seus gestos alongados e ritmados, como se marcassem a marcha

\}111 Conceição | Concept., Campinas, SP, v. 2, n. 2, p. 105-118, jul./dez. 2013 
fúnebre. Na mesma peça de Jooss, a figura da mãe movimentase suave e lentamente, com gestos prolongados e suplicantes dos braços, veiculando doçura, melancolia e tristeza profunda, contrastando com os saltitantes soldados de peito aberto, cujos movimentos representam coragem, aventura e ingenuidade.

Vemos nessas peças um entendimento da relação entre movimento e estado psicológico das personagens de um para um. Somente décadas depois Pina Bausch, discípula de Jooss, adicionaria maior complexidade à equação. Em Café Müller (1978), uma personagem feminina de peruca vermelha, sobretudo e saltos corre saltitante pelo palco, observando assustada as ações das outras pessoas sem nunca interferir. Seus solos têm movimentos contidos, pontuados, centrais, que não se apropriam do espaço. Em seus olhos ágeis, que às vezes se prolongam na visão de outros personagens, vemos o desejo sempre autoboicotado de aproximação. Diferentemente da figura da Mãe em A Mesa Verde, que representa todas as mães que perdem seus filhos na guerra, a mulher de peruca de Bausch não é arquetípica e suas ações denotam uma personalidade multifacetada e altamente contraditória. Seus atos não são nobres - é somente uma figura triste e solitária do cotidiano, perdida em seus saltos.

Enquanto no balé clássico a medida do bom bailarino se dá pelo número de piruetas ou pela altura da perna levantada no développé, nos treinamentos de Laban e muitos de seus discípulos é a qualidade harmônica do intérprete que mede sua capacidade de articulação e habilidade nos movimentos. Para ele, o corpo harmônico deveria integrar-se totalmente no movimento, de forma que a atenção a uma parte específica fragmentaria a ação tornando-a grotesca e desarmônica: "movimentos harmônicos requerem a conexão de todo o corpo - a concentração da atenção numa parte é consequentemente grotesca" (trecho do diário de Warren Lamb enquanto estudava no Art of Movement Studio, 1947-49. McCAW, 2006, p. 56).

Um exemplo simples de desenvolvimento harmonioso no tempo-espaço seria a sucessão, ou seja, o movimento que "corre" como uma onda pelo corpo sem interrupções - cada interrupção no trajeto deve ser dominada e ultrapassada. Outro exemplo seriam os movimentos em oposição, nos quais se deve conseguir opor partes diametralmente antagônicas como se uma linha percorresse o corpo e se esticasse igualmente em ambas as direções. Exemplo mais complexo de harmonia são as relações de afinidade entre qualidades dinâmicas e direções no espaço, sobre as quais Laban estabeleceu regras fixas em seu livro Choreutics. A partir dessas regras, ele desenvolveu a dinamosfera e a escala diagonal, os únicos momentos 
nos quais relaciona os campos por ele criados da Choreutics e da Eukinetics, que para ele eram áreas fundamentalmente distintas (seria Warren Lamb, anos mais tarde, que conseguiria aproximar de fato e fazer cruzamentos entre as duas áreas em suas pesquisas sobre Effort/Shape).

Para exercitar a relação harmoniosa no movimento, Laban desenvolveu exercícios de escalas, que se constituíam de sequências fixas no cubo, com direções e qualidades de esforço determinadas. Segundo ele, o exercício constante das escalas habilitaria o corpo a reconhecer os padrões harmônicos e se adaptar a eles, deixando vícios e incapacidades dinâmicas para trás.

Frequentemente Laban fazia disso quase um treinamento militar. Seu ensino da escala diagonal, por exemplo, exigia que cada movimento tivesse a orientação espacial exata assim como o processo preciso de variação do esforço. (...) Se um estudante se concentrasse em obter uma orientação mais ascendente, então mais do que provavelmente decorreria uma falha em seu esforço indireto. Laban notaria isso imediatamente. (...) Eu soube de uma aula que durou mais de três horas, estudantes cobertos de suor e desesperadamente desgastados, mas arrastando suas últimas energias para se adequar ao mestre.

Laban acreditava que esse treinamento militar ajudaria a incorporar as escalas no instrumento corporal e a fazer-lhes a segunda natureza, assim como a prática das escalas pelos pianistas transforma-as em parte de sua musicalidade sem a necessidade de recordação consciente (LAMB apud McCAW, 2006, p. 75).

Laban pretendeu encontrar regras para a relação entre qualidades de movimentos e direções no espaço, o que possibilitaria que todo um treinamento corporal e uma classificação fossem possíveis. Entretanto, notamos que as escalas tinham o intuito de estabelecer no corpo dos praticantes as equações harmônicas de maneira a impô-las como num treinamento. Daí vemos que ele percebia que a grande maioria das pessoas não se movia de acordo com elas. Corpos desarmônicos tinham que ser transformados pelo exercício para se afinarem com as regras que ele havia delineado. "Laban tinha um termo favorito para as pessoas que necessitavam de alguma forma de terapia: eram tortos [lopsided]" (LAMB apud McCAW, 2006, p. 173-5).

A partir de estudos aprofundados sobre as teorias de Laban, é possível notar, entretanto, que dentro delas mesmas há elementos que contradizem suas concepções harmônicas. Seus intensos estudos das formas platônicas perfeitas e suas direções no espaço em Choreutics (especialmente o octaedro, o cubo e o icosaedro) sugerem a total simetria do corpo em todas as direções. Porém, seus estudos em Eukinetics complicam a análise do espaço ao considerá-lo perceptivelmente 
não simétrico, ou seja, as relações sensoriais e afetivas com as diferentes direções não seriam idênticas mas sim fundamentalmente distintas.

Apesar de aparentemente desconhecer o trabalho de Laban, ao falar sobre a contradição no espaço perceptivo em geral, a crítica de arte americana Rosalind Krauss (1999) parece descrever com precisão a contradição intrínseca às ideias dele. Ela afirma que o indivíduo se sente atraído pela simetria espacial, entretanto sua sensação física seria fundamentalmente assimétrica. O corpo humano, por ter a visão ventralmente colocada, sente diferentemente tudo que está à frente do corpo em relação ao que está atrás; devido ao fato de o eixo principal em relação à gravidade ser o vertical e o ar habitar o tórax, sentimos com mais leveza a parte superior e com mais firmeza a parte inferior; e por sermos destros ou canhotos, sentimos uma diferença de poder e hierarquia entre o lado hábil e o inábil. Krauss segue seu argumento para considerações a respeito da teoria Lacaniana da fase do espelho, que considera essencial no ser humano a fissura entre seu desejo de completude (harmonia ao redor de um centro) e sua sensação de completa fragmentação (falta de harmonia e inexistência de centro). Para Lacan, é nessa fissura que o indivíduo se constitui, e portanto ele permanece para sempre incompleto, sentindo-se completo somente na fantasia de integração com o outro que passa a determinar suas relações afetivas.

Laban infere o estado de desarmonia como parte inseparável do sujeito, mas ele não se aprofunda nisso - afinal, seria contraditório com seu desejo de encontrar uma constituição física e psíquica harmônica nas bases da simetria platônica. Sendo assim, apesar de buscar "leis gerais da harmonia" dos movimentos como algo universal, a-temporal e a-histórico, estes conceitos labanianos parecem ser fruto de decisões arbitrárias e julgamentos estéticos, que se tornaram as bases que ele tanto buscava para alicerçar suas práticas corporais e executar julgamentos. Laban relaciona harmonia ao movimento integrado do corpo prezando alinhamento, equilíbrio, domínio do fluxo de energia em relação a um centro único. "O caminho e a porta de entrada para o outro mundo, ainda desconhecido, poderiam ser encontrados uma vez que as relações de harmonia fossem descobertas" (KANT, 2002, p. 49). Consequentemente, todo movimento que não se encaixe nas categorias prescritas seria necessariamente desarmonioso e provavelmente grotesco. Daí compreendermos sua crença (e de North) de que indivíduos que se movem desarmoniosamente necessitariam, provavelmente, de alguma terapia corporal para uma melhora psicológica. "O movimento, revelado 
em nossos gestos, movimentos inconscientes (movimentos de 'sombra'), posturas do corpo e nossas ações de trabalho são sempre 'nós'" (NORTH, 1972, p. 6). Sua crença nas leis harmônicas também justificaria seu julgamento de que povos com danças desarmônicas seriam menos civilizados.

\footnotetext{
"Laban pensava que a prática das Escalas era algo civilizado a se fazer, ao contrário das formas bárbaras ou primitivas de se mover. Em nossa civilização avançada nós poderíamos aspirar a nos mover de maneiras que fossem em harmonia com o cosmos num nível que civilizações anteriores não haviam tido sucesso em fazer" (LAMB apud McCAW, 2006, p. 97)
}

Ao acreditar que o movimento humano seguiria padrões específicos e universais, ele passou também a crer ser possível criar uma forma de notação que desse conta de descrever com precisão os movimentos do corpo. Sua escrita de movimentos, conhecida como Labanotação, divide o corpo em partes e associa um símbolo a cada uma delas. O espaço, simetricamente dividido a partir das formas platônicas, adquire direções definidas que também recebem símbolos específicos. A partir da relação entre parte do corpo e direção do movimento no espaço, sua escrita dá conta de descrever movimentos razoavelmente complexos.

Para conseguir anotar as qualidades dos movimentos Laban desenvolveu um outro gráfico inteligente, colocando as qualidades de resistência (tempo acelerado, peso firme, fluência controlada e espaço direto) de um lado e de entrega do outro (tempo sustentado, peso leve, fluência livre e espaço indireto). Entretanto, na sua Labanotação esses símbolos não são bem incorporados. A Labanotação é capaz de registrar quais partes do corpo se movem, em que direção e em que sincronia/assincronia. Mas os símbolos das qualidades ficam sempre soltos no papel, nas laterais, tentando entrar à força. Apesar do esforço, essas indicações ficam incompletas e é fácil compreender a frustração de Laban ao perceber que poderia analisar e registrar para sempre e com precisão para onde as pessoas se movem, mas não exatamente como. É fato que depois de observar, já na casa dos cinquenta anos, que sua notação não conseguia dar conta da parte qualitativa dos movimentos (os quatro fatores associados) com perfeição, ele abandonou seus estudos nessa direção e seus discípulos tiveram que terminá-la.

Albrecht Knust (1896-1978) coordenou este projeto gigantesco, que terminou somente nos anos 70, quando os 200 volumes da Kinetographie Laban foram depositados em somente dez bibliotecas de dança em todo o mundo. Apesar de seus arcaísmos e obscuridades Labanescas típicas, Labanotação é significativa por duas razões: 1) revelou que a maioria esmagadora das coreografias se confina a 
uma escala minúscula das possibilidades totais do movimento do corpo humano, que a imaginação coreográfica era incrivelmente cega em relação a um enorme potencial expressivo pouco explorado; e 2) mostrou que o corpo que dança produz distúrbios tão complexos de percepção que a análise empírica era muito mais difícil do que quase todo mundo havia pensado. De modo nenhum era fácil descrever exatamente os movimentos corporais, o que dizer de seus significados. Labanotação é como um dicionário imenso; fornece as letras e as palavras para descrever movimentos discretos, mas é impotente para explicar o significado dos movimentos que descreve, e também não consegue relacionar variações de sequências de movimento com variações semânticas (TOEPFER, 1997, p. 105-106).

6.

Analisar tanto os textos originais escritos por Laban quanto os desdobramentos efetuados por discípulos que o sucederam é fundamental para que consigamos avaliar a pertinência de seus conceitos hoje em dia. Praticamente um século depois de suas primeiras incursões nos campos ensolarados do Monte Verità, vemos que o uso de suas teorias enraizaram-se mundialmente em áreas das mais distintas - o que comprova que muito do que ele descobriu/criou ainda se mostra extremamente útil.

Entretanto, ainda observamos a aplicação de seus princípios de maneira muitas vezes cega, como se fossem verdades absolutas. É preciso salientar que as teorias de Laban não formam um sistema científico de análise de movimentos, como muitos erroneamente consideram. Aliás, há poucas comprovações científicas para suas ideias, apesar de haver atualmente esforços nessa área (Jeffrey Longstaff pesquisa a relação entre Choreutics e as leis da física, por exemplo). Muito pelo contrário, as ideias de Laban surgiram de seu desejo pessoal por construir uma religião do ato, a partir de sua crença (influenciada pela maçonaria e pela Rosa Cruz) de que ao encontrar as leis harmônicas do movimento conseguiria, como consequência direta, transformar o próprio ser humano.

Seu arcabouço teórico se constitui como uma prática iniciática e labiríntica, aprendida somente através da relação entre mestre e discípulo. Foi na sua mudança para a Inglaterra que as ideias de Laban foram se transformando num sistema, adequando-se às necessidades e contextos das sociedades onde acabaram por proliferar na segunda metade do século XX e início do XXI (especialmente Inglaterra e EUA). Tal transformação deu-se tanto pelo trabalho de Laban com o engenheiro industrial inglês F. C. Lawrence quanto pelo de seus discípulos diretos, especialmente sigurd Leeder, Albrecht Knust, Lisa Ullman, Marion North, Valerie Preston-Dunlop, Irmgard Bartenieff e Warren Lamb. 
Este artigo buscou mapear alguns desdobramentos importantes relacionados às ideias de Laban sobre harmonia, chegando às seguintes considerações: 1 . a crença de Laban na relação direta entre movimento e estado interno deu origem à crença de que seria possível acessar a alma/espírito através dos movimentos do indivíduo; 2 . um estudo sistematizado a partir das formas platônicas em Choreutics deu a Laban critérios para avaliar as qualidades de harmonia e desarmonia nos movimentos; 3. esses critérios, apesar de muitos ainda verem como "naturais" são, na verdade, resultado de escolhas arbitrárias que valorizam as qualidades de simetria, equilíbrio e centro único em detrimento das qualidades de assimetria, desequilíbrio e descentramento; 4. Laban acreditava que sociedades mais avançadas se desenvolveriam "naturalmente" no sentido da harmonia espacial nos movimentos, enquanto sociedades menos avançadas (ou primitivas) fariam uso de movimentos mais energéticos e cheios de variações de esforço; 5. atualmente há documentos originais que comprovam a ligação entre Laban e o Regime Nazista, destruindo o mito que perdurou mais de meio século; 6 . quando da mudança de Laban para a Inglaterra, aconteceram processos de renomeação, sendo talvez os mais importantes (1) a passagem da acepção de interioridade originalmente relacionada à alma/espiritualidade para o conceito mais prático de personalidade e (2) a conversão da dicotomia harmonia/desarmonia em integração/fragmentação; 6. apesar de renomeados, esses conceitos mantêm muitas das ideias originais de Laban, inclusive alguns de seus mais profundos preconceitos. 
BANNERMAN-HAIG, Sara. Primary Toll, 2002. Disponível em: 〈http://www.communitydance.org.uk/metadot/index.pl?id=2 2216\&isa=DBRow\&op=show\&dbview_id=17860 . Acesso em: 24 jun. 2009.

HEATFIELD, Adrian (org.) Live art and performance. Nova York: Routledge, 2004.

KANT, Marion. Laban's secret religion. In: BURT, Ramsay; FOSTER, Susan Leigh (org.) Discourses in dance. 2nd ed. London: Laban Centre, 2002. v.1.

KANT, Marion; KARINA, Lilian. Hitler's dancers: German modern dance and the Third Reich. New York and Oxford: Berghahn Books, 2004.

KATZ, Helena. Por uma dramaturgia que não seja uma liturgia da dança. In: Revista Sala Preta. Vol. 10 nº1. ECA/USP, 2010.

KRAUSS, Rosalind; BOIS, Yve-Alain. Formless, a user's guide. New York: Zone Books, 1999.

LABAN, R. A Life for Dance. Nova York: Theatre Arts, 1975.

LEVY, Fran J.. Dance movement therapy: a healing art. National Dance Association, American Alliance for Health, Physical Education, Recreation, and Dance, 1992.

MARKAND, Anna. Jooss the teacher: his pedagogical aims and the development of the choreographic principles of harmony. In: Choreography and dance. New York: Routledge, 1993. vol. 3, part 2, p. 45-51.

MCCAW, Dick. An eye for movement: Warren Lamb's career in movement analysis. London: Brechin Books Limited, 2006.

NORTH, Marion. Personality assessment through movement. London: MacDonald and Evans, 1972.

TOEPFER, Karl. Empire of ecstasy: nudity and movement in German body culture, 1910-1935. Berkeley: University of California Press, 1997. 